are proposed: protunicate, unitunicate and bitunicate Ascomycetes. The protunicate forms are those in which the ascospores are not violently projected, and the ascus walls of which break down when the spores are ripe. Although this novel proposal has some merit in that it directs attention to the ascus wall, it is doubtful if the protunicate Ascomycetes represent a natural assemblage, because such diverse groups as the Endomycetales, Aspergillales, Microascales, Coronophorales, Onygenales, Meliolales and Laboulbeniales are included.

Some modification to the classification of Basidiomycetes has also been made. There are two sub-classes, the Holobasidiomycetes and Phragmobasidiomycetes. Within the Holobasidiomycetes the following groups are included Aphyllophorales, Agaricales, Agaricogastrales, Gastrales, Phallales. The account of the Agaricogastrales is especially useful. The arrangement of the Phragmobasidiomy. cetes is more conventional, embracing Tremellales (inclusive of the Dacrymycetaceae), Auriculariales, Uredinales (with a masterly account of variation in life-cycles) and Ustilaginales.

Although the second edition is considerably longer than the first it is unfortunate that no space has been devoted to some recent developments. For example, there is no reference to the role of Olpidium as a virus vector, and the demonstration of heterothallism in $O$. brassicae. The appearance of new biotypes of Synchytrium endobioticum is ignored. The whole question of physiological specialization of pathogenic fungi is scarcely mentioned. Very little notice is given to the fine structure of fungi apart from figures of flagella of Allomyces and Saprolegnia. No details are given of fine structure of cell walls, septa, haustoria, or of yeast cells. Sansome's claims that some Saprolegniaceae and some Pythiaceae are diploid are not discussed. Sexual reproduction in the Mucorales is dealt with very briefly, and without reference to the work of Banbury and Plempel, or to the variation in content of germ sporangia in relation to mating type. The relationship of Endogone to phycomycetoid mycorrhiza is not mentioned. In the account of the Entomophthorales there is no mention of the variety of methods of conidial propulsion, and only the secondary adhesive conidia of Basidiobolus are figured. The relationship of certain Ascomycetes to their conidial states is treated very briefly. Although Cephalosporium and Gliocladium are mentioned as conidial states of Hypocrea, there is no mention of Trichoderma. It is not made clear that the macroconidia of the Hypocreaceae are phialospores, and while it is true to say that some Ophiobolus and Leptosphaeria species have Phoma-type pycnidia there are at least five other form-genera known. The genetical treatment is weak. There is no mention of heterothallism in yeast, of heterokaryosis and parasexuality in Aspergillus and Penicillium, of the tetrapolar condition or multiple alleles in Basidiomycetes. The function of the clamp connexion in ensuring redistribution of two compatible nuclei in a hyphal tip is not explained. Alternative suggestions for the mechanism of basidiospore discharge are not discussed, nor are the observations that basidiospores often carry an electrostatic charge. The significance of the divided gill of Schizophyllum is not given. There is no account of hyphal structure of polypore fruit bodies.

Many of the illustrations appeared in the earlier edition, copied from other authors. The best of the new figures are from the pen of $\mathbf{E}$. Müller illustrating Ascomycetes. A.lthough it is liberally illustrated, more half-tone photographs, especially of pathogenic fungi, would have further improved the text. A student would, for example, learn little of the habit of Plasmodiophora bassicae, Phytophthora infestans, Albugo candida, Entomophthora, Taphrina or the Ustilaginales. An irritating feature is the occasional use of different names for the same organism in figures and text, for example, Pyronema omphalodes and $P$. confluens, and Rhizina inflata and $R$. undulata.
There is a similar inconsistency in the use of Agaricus and Psalliota.

To sum up, this is not a book for a beginner. It lacks excitement and neglects many features of the 'biology' of fungi. A.s a source of ideas on phylogeny it is valuable provided that the ideas are treated with due caution. The style is terse and authoritetive, and apart from a few minor errors and misprints, its chief defects are in its omissions. It is well produced, but at 66 Swiss francs ( $₫ 57 s .3 d$.) it seems rather expensive. JoHn Wrister

\section{GERMAN AND ENGLISH DICTIONARY OF PHYSICS}

Dictionary of Pure and Applied Physics

Compiled by Dr. Louis de Vries and W. E. Clason. Vol. I: German-English. Pp. 367. 1963. Vol. 2: English-German. Pp. 341. 1964. (Amsterdam, London and New York: Elsevier Publishing Company.) 55s. each volume. $\mathrm{N}$ these two volumes, two of the leading scientific lexicographers of the present day have combined their efforts and produced a compact work of reference giving a good coverage of the field of pure and applied physics (a field which certainly lacked such a dictionary hitherto). The number of terms on each page is $80-100$, and so it can be seen that in more than 300 pages a very considerable vocabulary is presented. Although this includes words such as stehen and stellen, and phrases such as wie immer, the very great majority of the terms belong specifically to the field of physics. Adjective-noun and most other phrases are entered under the first word, which is convenient, although cross-references from the other words might have been worth the extra space needed. Entering $z u$ stark gedämpfi under stark is not likely to be useful (and there is no corresponding entry at schwach); is there not a case for an indexed thesaurus arrangement rather than an alphabetical arrangement in dictionaries such as these?

Dr. de Vries's habit of omitting any distinction of meanings, though mitigated by the restriction to physics, is still in evidence ("line, Jeitung, $f$, Stromkreis, $m$, Zeile, $f$, Linie, $f$, Schirmschrift, $f$ "), although oddly enough there is some attempt to make the distinction with nontechnical words: "serious (earnest), ernst"-_-serious (grave) presumably not being considered worth including, nor is it even given as an equivalent of schwer ('heavy, stout, strong, difficult').

The spellings are not always correct; one page contains "hydroxyle ions" (the same in the other volume) and "shell spektrum" (which becomes "shell sprectrum" in the other volume). American spellings appear to be used throughout, with no mention of British forms. But British terminology (for example, valve rather than tube) appears more or less randomly; of the relevant entries beginning with Röhre, thirteen use tube, ten valve, six both (and three neither). The compilers do not name their sources, but the material thus seems to have been incorporated somewhat uncritically. Morcover, a check of one page taken at random in Volume 1 showed that about three-quarters of the entries are essentially identical with entries in de Vries's German-English Science Dictionary, third edition, which costs about the same, and so anyone who already possesses the latter book will probably not be getting much for his money if he buys Volume 1 of the Dictionary of Pure and Applied Physics.

I am myself concerned almost exclusively with translation into English, and the German-English volume has been mainly considered. The English-German volume is by no means a mere inversion of the other, and should be equally useful to translators from English into German; but let us hope that these do not include many of the "students in science and technology in the United States" for whom (according to the preface printed in both volumes) the dictionary is also intended. J. B. SykEs 